\title{
REGRESSION ANALYSIS OF INTERACTIONS BETWEEN COMPETING SPECIES
}

\author{
E. L. BREESE and J. HILL \\ Welsh Plant Breeding Station, Aberystwyth
}

Received 19.ix.72

\begin{abstract}
SUMMARY
The method of investigating interactions in two-way tables by the regression analysis introduced by Yates and Cochran (1938) has been applied to data from competition diallel experiments with plant species reported by Williams (1962) and Norrington-Davies (1968). Arithmetic and logarithmic scales were used in both experiments and the relative advantages of these are briefly discussed.

Significantly high proportions of the interactions between species (row) and associates (column) effects were explained as differences between the linear regressions of individual performance on the associate values. Consequently the performance of the species in competition could largely be specified by three parameters. These were the species mean $(v)$, the regression coefficient $(b)$ and the mean effect of associates $(a)$, which respectively measured the general vigour of the species, its sensitivity to competition and its aggressiveness. These parameters jointly provided estimates of what we have termed the general competitive abilities of the species. Specific competitive abilities of particular mixtures are detected as significant deviations from the regression lines.

The parameters were used to derive formulae which provide descriptive and predictive measurements of the competitive advantage of species in particular combinations, and of the mixture performances relative to the performance of other mixtures or monocultures. The types of competition phenomena which could derive from a situation involving only general competitive abilities were shown to vary greatly and depended on the correlations between the three parameters in the experimental material.

The possible types of interactions between associated genotypes (competition, co-operation, antagonism, etc.) can be defined in terms of the general competitive ability parameters, or recognised as specific competitive abilities. It is thus suggested that the regression technique forms a useful approach to the discovery and classification of these effects among competing species.

The second experiment (Norrington-Davies, 1968) involved competition between grass species under four different treatments. Common regression lines constructed over all treatments indicated that response to competitive stress was to some extent similar to the response to other kinds of environmental stress. This raised the concept that some aspects of general competitive abilities could be determined from general response to limitation in environmental factors. The plant breeding implications of this are briefly discussed, particularly the possibility of predicting performance under competition from performance as spaced plants.
\end{abstract}

\section{InTRODUCTION}

A POPUlAR experimental design for the study of competition effects in plants is a diallel arrangement, whereby a set of genotypes are grown as monocultures and in all possible paired combinations. Densities and treatments are varied as required. The design has an analogy to the diallel cross used in the genetic assessment of a set of parents and all forms of analysis have affinity with, or are directly adapted from, genetic analysis. These include 
the models devised by Williams (1962), McGilchrist (1965), McGilchrist and Trenbath (1971) together with the analysis of reciprocal differences developed by Durrant (1965) and applied by Norrington-Davies (1967, 1968).

The present paper examines the merits of a different form of analysis. This involves a regression technique originally proposed by $Y$ ates and Cochran (1938) as a means of combining data from a number of experiments. More recently it has been extensively used in the analysis of genotypeenvironment interactions (e.g. Finlay and Wilkinson, 1963; Perkins and Jinks, 1968) whilst its use in connection with competition diallels has been discussed by Wright (1971) and briefly by Jacquard and Caputa (1970). Its application here assumes that the environment of a genotype under competition is largely conditioned by its neighbours (Mather, 1961). Thus in a competition diallel the column means may be used as an index of the performance of all genotypes under test when grown with a common associate (i.e. a common environment), and the regression of each individual in turn against this index provides a measure of its linear response (or sensitivity) to changing competition.

The usefulness of this approach is considered here by reference to data published by Williams (1962) and by Norrington-Davies (1968).

\section{ANALYSIS OF THE FIRST EXPERIMENT}

(Data of R. M. Moore and F. D. Williams, quoted by E. F. Williams, 1962)

\section{(a) Partitioning the variation}

Details of this experiment are given by Williams (1962). Briefly, a diallel design was employed to investigate the effects of competition among seven weed species. The experiment was carried out in pots, with two replicates, and the variate recorded was dry weight of tops, in grams per half-pot. Williams found that plot means and variances were positively correlated and that it was necessary to use a log transformation to homogenise the variances. For reasons which will become apparent, both the transformed data and the data on the original arithmetic scale (= nontransformed data) are analysed. These latter values which were obtained as the antilogarithms of the data given by Williams, are presented in table 1 .

Analyses of both sets of data are given in table 2. Basically the analysis partitions the total variance into rows (= species) and columns (= associates) effects and the interaction of these, the error being provided by differences between replicates. Unlike the analysis used by Williams, this analysis makes no attempt to partition the error variation into pot comparisons, nor does it take account of the different errors which may attach to pure versus mixed cultures, even though for the non-transformed data the errors from different yielding cultures are known to be heterogeneous. Nevertheless, the conclusions which can be drawn from this analysis are the same as those derived by Williams. Thus both species and associates effects are significant, with the effect of species being the greater; the interaction of these effects is also significant so that the species and associates effects are not additive on either an arithmetic or logarithmic scale of measurement.

We can now calculate the linear regressions of individual performance against the mean effect of associates in the way already discussed. The sum 
of squares measuring the species $\times$ associate interaction can then be partitioned into an item measuring the differences between the slopes of the regressions for the individual species and a residual item measuring the scatter of points about the regression lines. From this partitioning (see

TABLE 1

Dry weight (grams $\times 10$ ) of tops harvested from seven weed species, summed over two replicates. Data from Williams (1962)

\begin{tabular}{|c|c|c|c|c|c|c|c|c|}
\hline $\begin{array}{l}\text { Associate } \\
\text { Species }\end{array}$ & 1 & 2 & 3 & 4 & 5 & 6 & 7 & Mear \\
\hline 1 & $62 \cdot 6$ & $164 \cdot 7$ & $105 \cdot 4$ & $93 \cdot 6$ & $106 \cdot 3$ & $125 \cdot 0$ & $98 \cdot 3$ & \\
\hline 2 & $88 \cdot 8$ & $123 \cdot 4$ & $161 \cdot 6$ & 153.5 & 184.5 & $204 \cdot 7$ & $118 \cdot 3$ & \\
\hline 3 & $9 \cdot 3$ & $23 \cdot 8$ & $20 \cdot 3$ & 14.7 & 30 & 36.5 & $14 \cdot 2$ & \\
\hline 4 & 11.7 & 32.9 & $24 \cdot 4$ & $23 \cdot 2$ & $36 \cdot 8$ & $33 \cdot 2$ & 23.5 & \\
\hline 5 & 4.0 & $8 \cdot 3$ & 14.8 & $7 \cdot 8$ & 20.5 & 23.9 & $4 \cdot 4$ & \\
\hline 6 & $3 \cdot 1$ & $5 \cdot 6$ & $6 \cdot 1$ & 4.6 & 14.4 & $12 \cdot 2$ & $3 \cdot 1$ & \\
\hline 7 & 20.7 & $59 \cdot 6$ & $78 \cdot 0$ & $50 \cdot 3$ & $74 \cdot 4$ & $85 \cdot 6$ & $52 \cdot 0$ & \\
\hline Mean & $28 \cdot 6$ & 59.8 & $58 \cdot 7$ & $49 \cdot 7$ & $66 \cdot 8$ & $74 \cdot 4$ & 44.8 & \\
\hline
\end{tabular}

table 2) it is clear that whichever scale of measurement is used, a significant amount of the interaction is explained by differences between the slopes of linear regressions. Indeed the residual item is only just significant at the 5 per cent. level against the basic error.

TABLE 2

Analysis of variance of Williams' (1962) data: (a) arithmetic values as given in table 1; (b) transformed to $100 \times \log _{10}[($ weight in grams $)+1] ;(c)$ arithmetic values with species 2 omitted (d.f. are given in parentheses)

\section{Item}

Species (S)

Associates (A)

$\mathrm{S} \times \mathrm{A}$

Heterogeneity of linear regressions

Residual deviations

Differences between replicates accumulated over species and associates (error)

d.f.
6
6
36

6

30

49

M.S. (a)
$10,231 * * *$
$800^{* * *}$
$144^{* * *}$
$399 * *$
$92 *$

$92 *$

47

M.S. $(b)$
$37,609^{* *} *$
$4,750^{* * *}$
$237^{* *}$
$605^{* *}$
$164^{*}$

164*

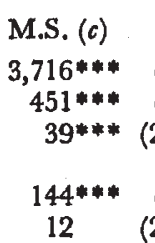

12

Throughout the tables the levels of significance are: $* \mathbf{P}=0.05-0.01 ; * * \mathbf{P}=0.01-$ $0.001 ; * * * \mathrm{P}<0.001$.

It follows that the performance of each species in competition can be largely predicted from the species mean and an appropriate function of the associates effect which is measured by the linear regression coefficient. The additive model given by Williams (1962, p. 512) can now be modified to describe the competitive situation in the experiment by incorporating the regression coefficient $(b)$. Thus, ignoring errors, $\mu$ is the grand mean of the experiment, $v_{i}$ is the mean deviation of the $i$ th species from $\mu, a_{j}$ the mean deviation from $\mu$ of associate $j$, and $b_{i}$ the regression coefficient of the $i$ th species (where $b_{i}=1+\beta_{i}$ of Perkins and Jinks, 1968). 


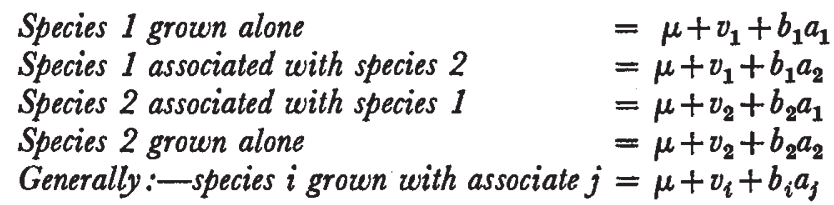

Although this largely represents the situation we must not forget the suggestively large residual effects and these will be discussed later (see also Wright, 1971).

\section{(b) Original data (arithmetic scale)}

Having established that the regressions provide measures of differential responses to decreasing competition (or sensitivities to increasing competition) we can consider what insight they provide into the way competition operates within this experiment. The regression lines for the arithmetic data are shown graphically in fig. 1, with points plotted for two of them to indicate the degree of scatter. The linear responses to decreasing competitive stress (represented by increasing values on the horizontal axis) resemble responses observed in other species and other experiments to improved environmental conditions (e.g. Perkins and Jinks, 1968; Breese, 1969). This obviously implies that decreasing competition equates with improved environmental conditions and that a competitor does no more than impose a specific limit on the environmental resources of its associate (see Mather, 1961).

There are of course a number of ways in which this limitation can be brought about. If it signifies no more than that strong competitors have a capacity for growth which secures unequal shares of limited environmental resources as proposed by Clements et al. (1929) and Donald (1963), then the average growth of the species should be completely correlated with the average amount by which the associates are repressed. In the present experiment this is not so, since the correlation between species and associates effects calculated from table 1 , although negative, is not complete $(r=-0.49)$. Inspection of the means shows that species 2 is anomalous in this respect since it has the highest mean value, but is only intermediate in its effect as an associate. If this species-array is removed from the experiment, the correlation between the remaining species and associates becomes significantly negative $(r=-0.92 *)$. For these remaining six species we can then infer that their interrelationships in association may be largely a question of securing a share of limited environmental resources (= competition in the purest sense), with the larger plants increasing at the expense of the smaller.

In this situation a number of points follow which are visually apparent from the graphs and can also be estimated from the statistics (see later). First we note that the species mean values and the regression values are positively correlated $\left(r=0.97^{* * *}\right)$. Thus the more productive species are also most sensitive to competitive stress. Since performances in monoculture and mixtures are on the whole specified by the same response regression line for each species, it follows that the strongest competitor is likely to be its own worst enemy in so far as individual performance is concerned (see for instance species 1 in table 1 ). It should be noted at this point that an important consequence of the present analysis is that the dynamic measures afforded by the regressions place monocultures and mixtures on the same footing. The full significance of this is discussed later. 
We have noted that species 2 differs from the other 6 in that its competitive ability measured by mean and regression is not matched by a corresponding repressive effect on its associates. Apparently this species has some feature

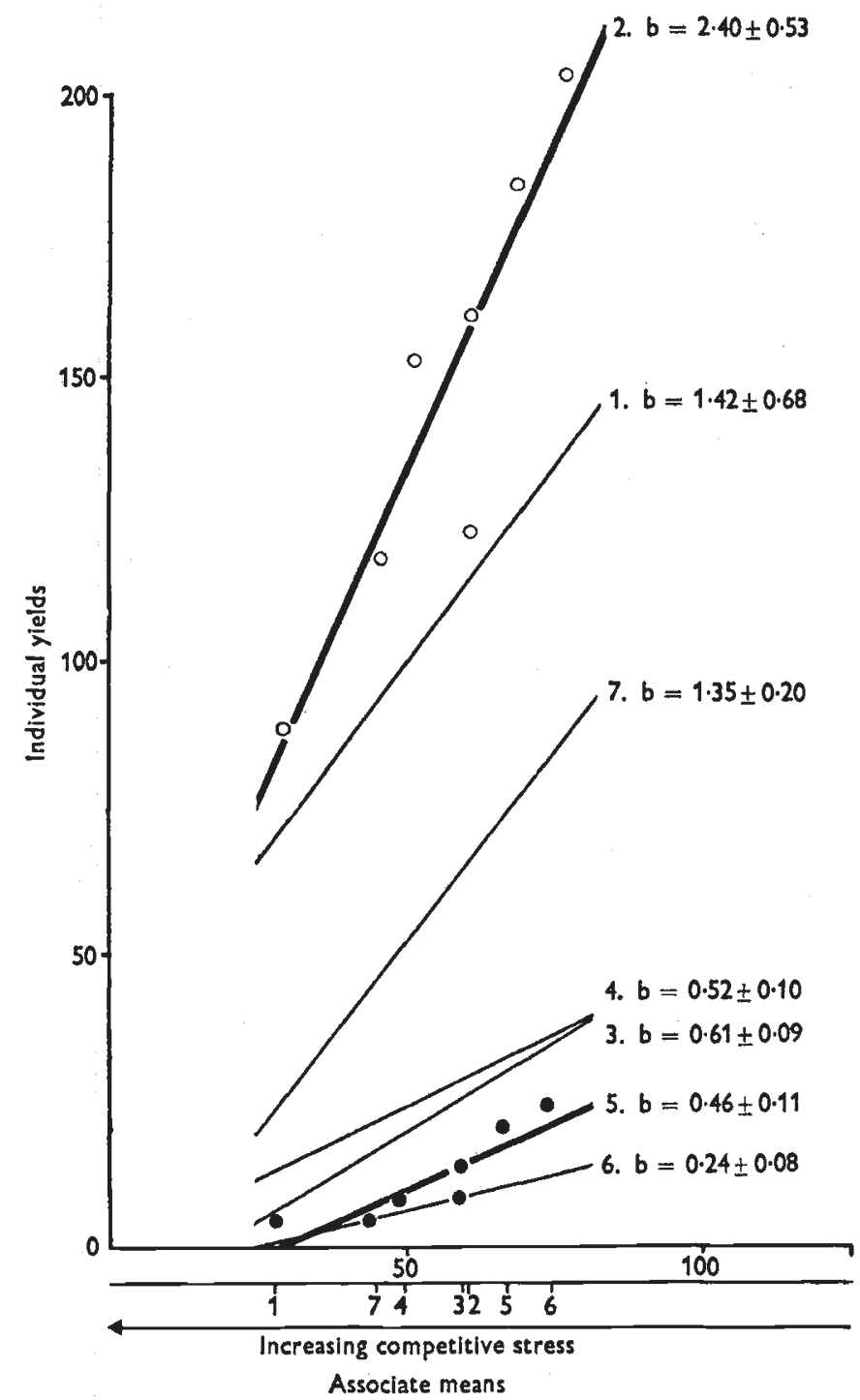

Fig. 1.-Regressions of individual yields on environmental mean yields-non-transformed data from Moore and Williams' experiment (Williams, 1962).

which causes it to be generally less aggressive with associates than the other species. In the absence of further biological information on the species we can only speculate what this may be. It may have a special tolerance of plant exudates (Evenari, 1961) or it may occupy a slightly different niche in space or time from its associates (de Wit, 1960). The latter cause is to some extent indicated in that its performance in monoculture is rather less 
than expected from its performance in mixtures (i.e. the point for monoculture performance deviates most markedly from the regression line in fig. 1). This observation prompted a re-analysis of the data omitting species 2. The results, given in the third column of table 2, show that after fitting the regressions for the remaining six species there is now no significant residual interaction. Significant deviations from regressions indicated by the significant residual item in the full analysis are evidently a feature of species 2 only, but we have not carried the analysis further to determine whether the effect is specific to its monoculture or whether it involves one or more of its mixtures.

From these analyses it is clear that we are dealing with two types of competitive ability: here defined as general competitive ability, which is measured for each species by its mean and regression coefficient, and specific competitive ability which is a feature of individual mixtures or monocultures and is detected by deviations from the regression lines. The former seems to be of major importance in the present experiment.

\section{(c) The transformed data (log scale)}

A log transformation of the data was carried out by Williams (1962) in order to remove the correlation between mean and variance, and so ensure that the scalar conditions for an analysis of variance were more strictly realised. That the transformation has been effective in doing this is evident from table 3, where the mean squares for the residual scatter of points about each regression line are given. For the non-transformed data these residual

TABle 3

Bartlett's test of homogeneity of variance on the regression error mean squares of $(a)$ the non-transformed, and (b) the transformed data of Williams (1962), together with the correlation of these mean squares with competitor means ( $r$ )

\begin{tabular}{lccccccccc} 
Species & 1 & 2 & 3 & 4 & 5 & 6 & 7 & \multicolumn{1}{c}{$\chi_{\text {[6] }}^{2}$} & $r$ \\
M.S. (a) & 626.19 & 376.06 & 11.16 & 13.31 & 16.63 & 7.98 & 55.41 & $45.85^{* * *}$ & $0.84 *$ \\
M.S. (b) & 334.62 & 98.41 & 72.14 & 220.33 & 498.16 & 429.90 & 305.53 & 6.85 & -0.52
\end{tabular}

variances are positively correlated with the mean, whilst Bartlett's test indicates that they are significantly heterogeneous. After transformation, however, the heterogeneity is no longer significant. On the log scale therefore all regression lines are estimated with equal precision.

As we saw earlier (table 2), the transformation in no way removes the interaction between the effects of associates and species and so does not provide a scale on which these effects can be dealt with additively. But it profoundly influences the relative slopes of the regressions and thus alters the picture presented by the graphs. Instead of the regression lines diverging as the suppressing effect of associates weakens (i.e. the upper end of the scale) they now converge (fig. 2) so that the positive correlation between means and regression coefficients on the linear scale $\left(r=0.97^{* * *}\right)$ becomes negative on the log scale $\left(r=-0.86^{*}\right)$. This merely indicates that differences between the species increase at a rate which is less than logarithmic as the competitional stress weakens. Although the relative rates of change can be measured by the regression coefficients on either scale, the use of logarithms introduces 
an abstraction which complicates both the visual interpretation of the graphs and the use of the estimated parameters in predicting response. Consequently for most purposes it is thought easier to use linear measurements

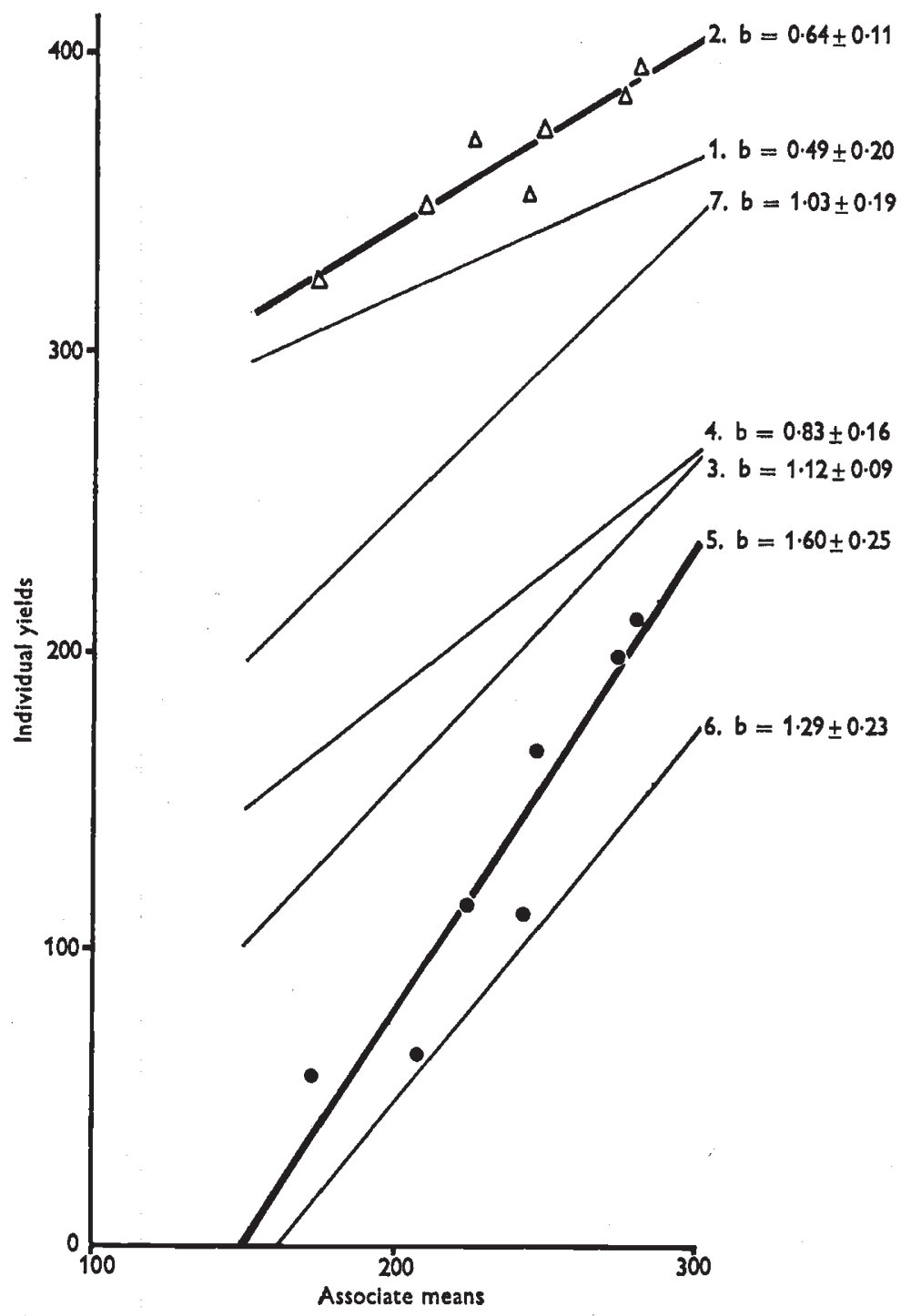

Fig. 2.-Regressions of individual yields on environmental mean yields-data transformed to $100 \times \log _{10}$ [(weight in grams) +1] (Williams, 1962).

and accept, with due caution, the inaccuracies of combining non-homogeneous error variances.

(d) The measurement of competitive advantage

The means and regressions can be used to formulate the competitive advantage $(S)$ of species $i$ over species $j$ in mixture $i j$ at the time of harvest. 
Thus, from formula (1):

$$
\begin{aligned}
S \text { of } i \text { over } j & =\mu+v_{i}+b_{i} a_{j}-\mu-v_{j}-b_{j} a_{i} \\
& =v_{i}-v_{j}+b_{i} a_{j}-b_{j} a_{i} .
\end{aligned}
$$

Formula 2 emphasises the interdependencies of varietal means and the regression values (sensitivity to competition) as well as the effect on associates (aggressiveness), all of which can thus be recognised as components of general competitive ability. For example, species 2 has a low aggressiveness rating but maintains a competitive advantage with all species except species 1. This is apparent from the graph and individual expectations may be calculated from the formula. However, the competitive advantage of species 1 over 2 in their mixture $(S=15 \cdot 7)$ is much less than observed ( $=75.9$ in terms of the yield values of table 1 ), which again points to the specific competitive interactions detected for mixtures involving species 2 in the previous analyses.

\section{(e) Total yields of mixtures and monocultures}

So far we have considered the regression analysis in relation to measuring and predicting competitive advantage. This has particular interest with regard to population dynamics and evolutionary trends. In considering the agronomic potential of crop plants the total yields of mixtures relative to each other and to monocultures are also of importance and the analytic components are no less useful in measuring and predicting these. A few simple formulae are considered below.

In a 50:50 mixture of species $i$ and $j$ (again ignoring residual and error effects) formula 1 can be expanded to specify the total yield $(r)$

$$
Y_{i j}=2 \mu+v_{i}+v_{j}+b_{i} a_{j}+b_{j} a_{i} .
$$

The basis of most other analyses of competition experiments lies in the comparison of mixtures with the component species grown as monocultures. This comparison may be considered in the present analysis as a special case. Thus the deviation $(C)$ of the yield of mixture $i j$ from the mean yield of the monocultures can be expressed as:

$$
\begin{aligned}
C & =r_{i j}-\frac{1}{2}\left(r_{i i}+Y_{j j}\right) \\
& =2 \mu+v_{i}+v_{j}+b_{i} a_{j}+b_{j} a_{i}-2 \mu-v_{i}-v_{j}-b_{i} a_{i}-b_{j} a_{j} \\
& =b_{i}\left(a_{j}-a_{i}\right)+b_{j}\left(a_{i}-a_{j}\right) \\
& =\left(b_{i}-b_{j}\right)\left(a_{j}-a_{i}\right) .
\end{aligned}
$$

This term will only be zero where there is no heterogeneity of regressions (i.e. no interactions explained in this way) or no differences between the effects on associates. Otherwise the mixture yield will be complemented to an extent which depends on the balance of their relative sensitivities to competition and their aggressiveness to associates, measured by $b$ and $a$ respectively. This complementation $(C)$ in mixture yield will be positive if the $b$ 's and $a$ 's are negatively associated; it will be negative if they are positively associated in which case inhibition in one or both constituents will be implied. In the first instance complementation may be regarded as a "dominance" effect of one species over another. Like genetic dominance it can be defined as partial, complete, or over-complementation depending on 
whether it is less than, equal to, or exceeds either monoculture (taking sign into account). The latter effect is realised if

$$
C>\frac{1}{2}\left(r_{i i}-\Upsilon_{j j}\right)
$$

where $i$ is the highest yielding monoculture. This formula can be expanded to give the condition that

$$
\left(b_{i}-b_{j}\right)\left(a_{j}-a_{i}\right)> \pm\left(v_{i}-v_{j}+b_{i} a_{i}-b_{j} a_{j}\right)
$$

the + or - sign being necessary to define the direction of the effect; i.e. whether it is better than the best monoculture or worse than the poorest (= negative over-complementation or mutual inhibition). The formula may also be expressed as a ratio, where values less than 1 will specify partial complementation and values over 1 will indicate over-complementation.

Formula 5 can be contrived to give positive values. For instance this situation is met where the left-hand term is maximised through a negative association of $b$ and $a$ values, and the right-hand term is minimised through a minimal or negative association of $v$ and $b$ values (and thus a minimal or positive association between $a$ and $v$ values). We can imagine that this situation exists where plants of low aggressiveness and low sensitivity to competitional stress (e.g. plants able to tolerate shade or plant exudates) are grown with plants with a high response to any decrease in competitive stress. But the reality of such a situation can only be determined by experiment.

For six of the species in the present experiment (excluding species 2) $b$ values are almost completely negatively correlated with $a$ values, while $v$ is positively correlated with $b$. Thus partial or complete positive complementation is predicted and observed for most mixtures, but over-complementation is neither predicted nor observed in any case within the limits of experimental error. As noted earlier, species 2 is exceptional in having a high mean yield and a low aggressiveness rating. It also shows marked deviations from the regression lines and hence interactions which are specific to particular mixtures. It can be shown that its monoculture yield is less than predicted from the means and regressions, while its mixture with species 1 is higher yielding than predicted and borders on over-complementation. Again this suggests that this species may occupy a different niche in time or space from the other associates.

\section{ANALYSIS OF THE SECOND EXPERIMENT}

(Data of 7. Norrington-Davies, 1968)

\section{(a) Regression analysis}

The experiment conducted by Norrington-Davies (loc. cit.), who also employed a diallel arrangement, was designed to examine competition amongst five grass species (represented by cultivars shown in brackets), namely Phleum bertelonii (S.50), Festuca pratensis (S.53), Lolium perenne (S.23), Lolium multiflorum (S.22) and Dactylis glomerata (S.143). This material was grown in pots at two contrasting levels of soil fertility (low $S_{1}$ and high $S_{2}$ ). Half the experiment was harvested 136 days after sowing $\left(H_{1}\right)$ whilst the remainder was harvested 198 days after sowing $\left(H_{2}\right)$. Tiller number and dry weight were recorded for all the plants harvested, though in the present paper we shall consider only the dry weight data. There were two replications. 
The results are summarised in table 4 , while analyses of the original and $\log$ transformed data are presented in table 5 . Here the use of regression analysis offers an unusual way of combining the data from all four treatments

TABLE 4

Mean plant dry weight $(g \times 100)$ of five grass cultivars summed over two replicates (Norrington-Davies, 1968). Table A gives the results of plants grown in a field soil $\left(S_{1}\right)$ and table $B$ of those grown in Fohn Innes Compost $\left(S_{2}\right)$. $H_{1}=$ first harvest, $H_{2}=$ second harvest

A $\left(S_{1}\right)$

\begin{tabular}{|c|c|c|c|c|c|c|c|c|c|c|c|c|}
\hline \multirow[b]{2}{*}{$\begin{array}{l}\text { Associat } \\
\text { Species }\end{array}$} & \multicolumn{6}{|c|}{$H_{1}$} & \multicolumn{6}{|c|}{$\mathrm{H}_{2}$} \\
\hline & e $S .50$ & S.53 & S.23 & S.22 & S.143 & Mean & S.50 & S.53 & S.23 & S.22 & S.143 & Mear \\
\hline S.50 & 65 & 30 & 32 & 19 & 41 & $37 \cdot 4$ & 293 & 451 & 180 & 79 & 351 & $270 \cdot 8$ \\
\hline S.53 & 50 & 51 & 39 & 19 & 75 & 46.8 & 248 & 255 & 155 & 41 & 211 & 182 \\
\hline S.23 & 117 & 105 & 78 & 40 & 124 & 92.8 & 521 & 560 & 259 & 151 & 508 & 399.8 \\
\hline S. 22 & 197 & 192 & 162 & 119 & 156 & $165 \cdot 2$ & 821 & 751 & 564 & 364 & 806 & $661 \cdot 2$ \\
\hline S.143 & 67 & 73 & 67 & 35 & 47 & 57.8 & 368 & 292 & 167 & 111 & 289 & $245 \cdot 4$ \\
\hline Mean & 99.2 & 90.2 & $75 \cdot 6$ & 46.4 & 88.6 & 80.0 & $450 \cdot 2$ & 461.8 & 265.0 & 149.2 & 433.0 & 351.8 \\
\hline
\end{tabular}

B $\left(S_{2}\right)$

\begin{tabular}{|c|c|c|c|c|c|c|c|c|c|c|c|c|}
\hline \multirow[b]{2}{*}{$\begin{array}{l}\text { Associat } \\
\text { Species }\end{array}$} & \multicolumn{6}{|c|}{$H_{1}$} & \multicolumn{6}{|c|}{$H_{2}$} \\
\hline & e $S .50$ & S.53 & S.23 & S.22 & S.143 & Mean & S.50 & S.53 & S.23 & S.22 & S.143 & Mean \\
\hline S.50 & 117 & 92 & 100 & 28 & 90 & 85.4 & 917 & 964 & 501 & 151 & 720 & $650 \cdot 6$ \\
\hline S.53 & 61 & 82 & 56 & 26 & 84 & 61.8 & 526 & 638 & 296 & 82 & 563 & 421.0 \\
\hline S.23 & 154 & 118 & 126 & 52 & 147 & $119 \cdot 4$ & 1156 & 1254 & 765 & 324 & 1045 & 908.8 \\
\hline $\mathrm{S} .22$ & 282 & 395 & 374 & 210 & 359 & $324 \cdot 0$ & 1923 & 1697 & 2026 & 1042 & 1560 & $1649 \cdot 6$ \\
\hline S.143 & 111 & 99 & 77 & 32 & 100 & 83.8 & 772 & 864 & 452 & 135 & 774 & $599 \cdot 4$ \\
\hline Mean & 145.0 & 157.2 & $146 \cdot 6$ & $69 \cdot 6$ & $156 \cdot 0$ & 134.9 & $1058 \cdot 8$ & $1083 \cdot 4$ & $808 \cdot 0$ & 346.8 & $932 \cdot 4$ & 845.9 \\
\hline
\end{tabular}

(see Yates and Cochran, 1938). Each associate value in each nitrogen and cutting treatment is used as an estimate of environmental stress and estimates of regression for the species are then obtained from all 20 points taken together.

TABLE 5

Analysis of Norrington-Davies' data: (a) mean plant dry weight in grams $\times 100$ and (b) $100 \log _{10}$ (grams dry weight $\times 10$ )

\begin{tabular}{|c|c|c|c|}
\hline Item & d.f. & M.S. (a) & M.S. (b) \\
\hline Species (S) & 4 & $8579 * * *$ & $5301^{* * *}$ \\
\hline Associates (A) & 19 & $5971 * * *$ & $3997 * * *$ \\
\hline $\mathbf{S} \times \mathbf{A}$ & 76 & $353 * * *$ & $43 * * *$ \\
\hline Heterogeneity of linear regressions & 4 & $4870^{* * *}$ & $199 * * *$ \\
\hline Residual deviations & 72 & $102 * * *$ & $35^{* * *}$ \\
\hline $\begin{array}{l}\text { Differences between replicates } \\
\text { accumulated over species, associate } \\
\text { harvests and fertility levels (error) }\end{array}$ & 100 & 25 & 15 \\
\hline
\end{tabular}

For the original data the analysis of variance shows that a large and significant proportion of the total species $\times$ associate interaction is attributable to differences between the slopes of the linear regressions. Because the residual item is also highly significant when tested against the experimental error, a degree of non-linearity must still exist in the species/associate relationship. 
This could be due to interactions which are specific to individual combinations, as previously discussed, or it could be due to a change in expression from treatment to treatment.

The regression slopes are depicted for the arithmetic scale in fig. 3 and for the log scale in fig. 4. Points are plotted for two of the species for purposes of illustration. The overlap of associate values from the different treatments is

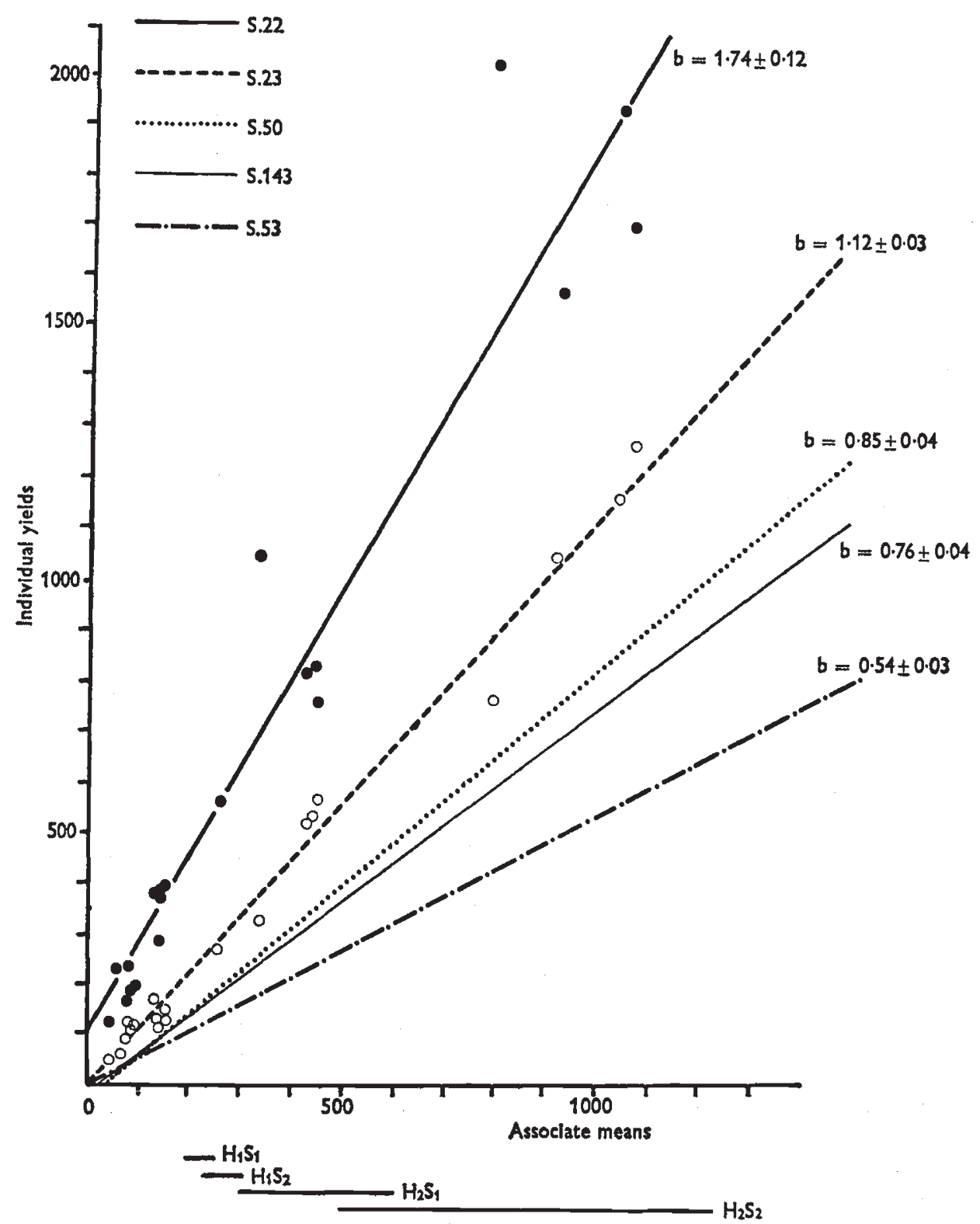

FIG. 3.-Regressions of individual yields on environmental mean yields-untransformed data from Norrington-Davies (1968). 
shown along the horizontal axis and indicates the way in which the graphs incorporate relative responses to differences in time, available resources and stresses imposed by competition. Yet the continuum of points for all species

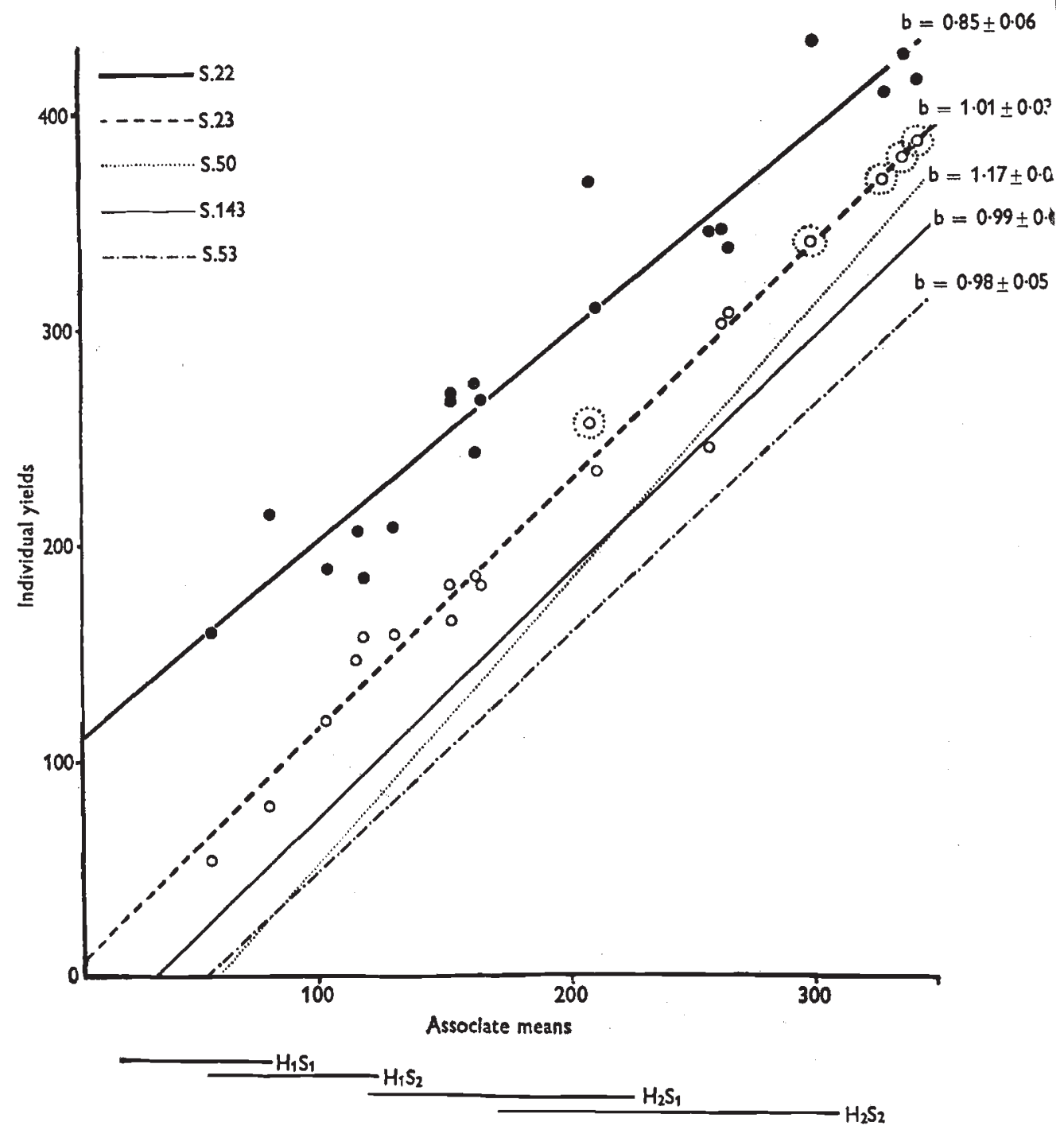

FrG. 4. - Regressions of individual yields on environmental means yields-data from Norrington-Davies (1968) transformed to $100 \log _{10}$ (grams dry weight $\times 10$ ).

falls effectively on the same straight line. Indeed none of the species on the arithmetic scale, and only $\mathbf{S . 2 3}$ on the log scale, exhibit heterogeneity in response curves when these are estimated separately for each treatment. It is appreciated that the latter is not a critical test considering the errors attached to the lines (see fig. 3). Nevertheless, it would appear that the responses to limitations in the environment imposed by competing associates do not differ in kind from those imposed by time or by other environmental agencies. 
The analysis of the transformed data is interesting. The mean square measuring the interaction of species and associates is still significant (table 5) but can be seen to account for a smaller proportion of the total sum of squares than when the untransformed data were used. This suggests that changing the scale of measurement has reduced the interactions. Differences between the slopes of the regressions again account for a significant part of the interaction effects while the residual is still significant against basic error. As with Williams' (1962) data, the log transformation effectively removes the correlation between means and variance and this is reflected by the homogeneous variances of the regression slopes (table 6).

TABLE 6

$\chi^{3}$ values obtained from the Bartlett's test of homogeneity of variance for the regression error mean squares of (a) the original data; (b) the transformed data of Norrington-Davies (1968). The values within each variety are calculated over the four combinations of soil fertility and time of harvest

(a)

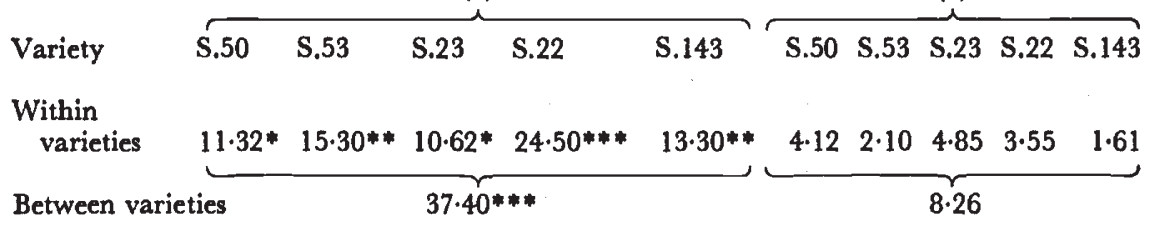

Comparing figs. 3 and 4 we can see that $\log$ transformation of the data has again profoundly affected the slopes of the regressions. The difference between the coefficients are vastly reduced, which will of course be reflected in the reduced mean square for species/associates interactions on this scale (table 5). Three of the regression lines (S.23, S.143 and S.53) are practically parallel, with slopes near unity, indicating that their response to less restrictive conditions is essentially logarithmic. For these three species, therefore, species, associates and treatment effects are largely additive on this scale. S.22 and S.50, on the other hand, have unique responses to better environments, the rate of change being less than logarithmic in the former and more than logarithmic in the latter.

\section{(b) Competitive advantage and mixture yields (arithmetic scale)}

The regression coefficients are positively correlated with the species mean values over treatments so that the differences between species increase with time and with increasing level of nitrogen. Both these parameters are negatively correlated with associate values within treatments and thus differences brought about by competition will also increase over this range of treatments. This is well illustrated in table 7 , where the competitive advantage $(S)$ of species $i$ in mixture $i j$, calculated from formula 2 for each treatment separately, is given for four of the mixtures. In each case the competitive advantage increases progressively and markedly from the first harvest with low nutrients to the second harvest under high nutrients. The observed values, calculated directly from table 4 , show the same trend and a reasonable correspondence with expectation.

The four mixtures considered in table 7 are chosen as representative of all 
10 mixtures in the diallel arrangement in order that parameters derived from the statistics may be considered in more detail. From the estimates of competitive advantage $(S)$ it will be seen that the stronger competitor is usually consistently so in all treatments, but becomes strongest in the highest yielding treatment ( $=$ the best environment). The only exception is S.50 which is generally the weakest competitor in the lowest yielding treatment

TABLE 7

Changes in the competitive advantage $(S)$, complementation $(C)$ and complementation ratio $(C R)$ of four representative mixtures over treatments using the original data of Norrington-Davies (1968). Expected values were calculated from formulae 2, 4 and 5 respectively

\begin{tabular}{|c|c|c|c|c|c|c|}
\hline \multirow{2}{*}{ Mixture } & & \multirow[b]{2}{*}{ Effect } & \multicolumn{4}{|c|}{ Treatment } \\
\hline & & & $H_{1} S_{1}$ & $H_{1} S_{2}$ & $H_{2} S_{1}$ & $H_{2} S_{2}$ \\
\hline \multirow[t]{3}{*}{ S.22/23 } & $S$ & $\left\{\begin{array}{l}\text { Expected } \\
\text { Observed }\end{array}\right.$ & $\begin{array}{l}181 \\
122\end{array}$ & $\begin{array}{l}278 \\
322\end{array}$ & $\begin{array}{l}395 \\
413\end{array}$ & $\begin{array}{l}1118 \\
1702\end{array}$ \\
\hline & C & $\left\{\begin{array}{l}\text { Expected } \\
\text { Observed }\end{array}\right.$ & $\begin{array}{r}18 \\
5\end{array}$ & $\begin{array}{l}48 \\
90\end{array}$ & $\begin{array}{l}72 \\
92\end{array}$ & $\begin{array}{l}286 \\
543\end{array}$ \\
\hline & $C R$ & $\left\{\begin{array}{l}\text { Expected } \\
\text { Observed }\end{array}\right.$ & $\begin{array}{l}0.19 \\
0.13\end{array}$ & $\begin{array}{l}0.83 \\
1.08\end{array}$ & $\begin{array}{l}1 \cdot 13 \\
0.88\end{array}$ & $\begin{array}{l}1.42 * \\
1.96\end{array}$ \\
\hline \multirow[t]{3}{*}{ S.22/53 } & $S$ & $\left\{\begin{array}{l}\text { Expected } \\
\text { Observed }\end{array}\right.$ & $\begin{array}{l}230 \\
173\end{array}$ & $\begin{array}{l}334 \\
369\end{array}$ & $\begin{array}{l}821 \\
710\end{array}$ & $\begin{array}{l}1796 \\
1615\end{array}$ \\
\hline & $C$ & $\left\{\begin{array}{l}\text { Expected } \\
\text { Observed }\end{array}\right.$ & $\begin{array}{l}52 \\
41\end{array}$ & $\begin{array}{l}105 \\
129\end{array}$ & $\begin{array}{l}375 \\
173\end{array}$ & $\begin{array}{r}884 \\
99\end{array}$ \\
\hline & $C R$ & $\left\{\begin{array}{l}\text { Expected } \\
\text { Observed }\end{array}\right.$ & $\begin{array}{l}0.41 \\
0.61\end{array}$ & $\begin{array}{l}0.78 \\
1.01\end{array}$ & $\begin{array}{l}3.46 \\
1.59\end{array}$ & $\begin{array}{l}7.58 \\
0.25\end{array}$ \\
\hline \multirow[t]{3}{*}{ S.23/53 } & $s$ & $\left\{\begin{array}{l}\text { Expected } \\
\text { Observed }\end{array}\right.$ & $\begin{array}{l}58 \\
66\end{array}$ & $\begin{array}{l}94 \\
62\end{array}$ & $\begin{array}{l}371 \\
405\end{array}$ & $\begin{array}{l}775 \\
958\end{array}$ \\
\hline & $C$ & $\left\{\begin{array}{l}\text { Expected } \\
\text { Observed }\end{array}\right.$ & $\begin{array}{r}8 \\
15\end{array}$ & $\begin{array}{r}6 \\
-34\end{array}$ & $\begin{array}{l}114 \\
201\end{array}$ & $\begin{array}{l}160 \\
147\end{array}$ \\
\hline & $C R$ & $\left\{\begin{array}{l}\text { Expected } \\
\text { Observed }\end{array}\right.$ & $\begin{array}{l}0.24 \\
0.56\end{array}$ & $\begin{array}{r}0.08 \\
-0.78\end{array}$ & $\begin{array}{r}2.53 \\
50 \cdot 25\end{array}$ & $\begin{array}{l}0.50 \\
1.16\end{array}$ \\
\hline \multirow[t]{3}{*}{ S.50/53 } & $s$ & $\left\{\begin{array}{l}\text { Expected } \\
\text { Observed }\end{array}\right.$ & $\begin{array}{r}-3 \\
-20\end{array}$ & $\begin{array}{l}29 \\
31\end{array}$ & $\begin{array}{l}123 \\
203\end{array}$ & $\begin{array}{l}323 \\
438\end{array}$ \\
\hline & $C$ & $\left\{\begin{array}{l}\text { Expected } \\
\text { Observed }\end{array}\right.$ & $\begin{array}{r}-3 \\
-36\end{array}$ & $\begin{array}{r}4 \\
-46\end{array}$ & $\begin{array}{r}4 \\
151\end{array}$ & $\begin{array}{r}8 \\
-65\end{array}$ \\
\hline & $C R$ & $\left\{\begin{array}{l}\text { Expected } \\
\text { Observed }\end{array}\right.$ & $\begin{array}{l}-0.32 \\
-2.58\end{array}$ & $\begin{array}{r}0.33 \\
-1.32\end{array}$ & $\begin{array}{l}0.04 \\
3.98\end{array}$ & $\begin{array}{r}0.03 \\
-0.24\end{array}$ \\
\hline
\end{tabular}

* S.23 monoculture predicted to outyield S.22 monoculture, but this was not observed.

but finally becomes a stronger competitor than S.53 (and also S.143) as yielding conditions improve. This is predicted generally from the graphs (figs. 3 and 4 ) where the regression line for $\mathrm{S.50}$ crosses over the lines for S.53 and S.143.

We can now turn our attention to changes in the total yields of mixtures from treatment to treatment. Again, we can specifically consider the complementation effect $(C)$ which is the deviation of the mixture yield from the mean monoculture yields of the constituent species. These values, calculated from formula 4 , are given for the four sample mixtures in table 7 . 
Clearly, positive complementation is of widespread occurrence in this experiment, but it is noteworthy that its expression increases over treatments with time and nutrient supply. Increased yield in the strong competitor is thus greater than depression in yield of the weaker competitor. The S.50/53 mixture is again exceptional in that the yield of the mixture is depressed in the lowest yielding treatment (i.e. negative complementation or inhibition).

Finally, we can consider whether there is any evidence of over-complementation; i.e., where mixtures outyield the best monocultures. To this end, the complementation ratios $(C R)$ derived from formula 5 have been calculated. These are also given in table 7 as expected values. Since this is the ratio of complementation $(C)$ to half the difference between monocultures, values greater than 1 indicate over-complementation. No over-complementation is predicted for the first harvest at either nutrient level for the four mixtures presented in the table. At the second harvest over-complementation is predicted for three of the four mixtures in the table at the low nutrient level and for two of the mixtures at the high nutrient level.

Here we make no attempt to estimate the standard errors of these values since we are at this stage only concerned to demonstrate the application of the regression method and consider what general conclusions may be drawn. These errors will be high because there is a considerable amount of species $x$ associate interaction which is not accounted for by linear regression. Observed values calculated directly from table 4 are also given. Again no errors are attached but there is a fair agreement with the predicted values except for the S.50/53 mixtures. Thus positive over-complementation is observed in four out of the five cases predicted. It should be noted that the complementation ratio (like the genetic "potence ratio") can take any value from 0 to $\infty$, the latter obtaining with any deviation provided the monocultures have equal value. It is because of this equality in yields of the constituent monocultures that the observed $C R$ value of the $\mathrm{S} .23 / 53$ mixture is so high in treatment $H_{2} S_{1}$.

If the $C R$ analysis illustrated in table 7 is extended to the whole of the data in table 4, it again emphasises that the amount of over-complementation varies with treatment. It is barely observed and never predicted at the first harvest at either nutrient level. The results for the second harvest are noteworthy in that over-complementation is apparent from the observed values of table 4 for all but one of the mixtures under the low nutrient level; six of which are predicted from regression formula 5. On the other hand, five mixtures are predicted to show over-complementation under the high nutrient level but only two are observed to do so in table 4 .

This situation presents a number of points of interest. In the first place variation in $a$ (aggressiveness) over treatments is such that over-complementation in some mixtures is predicted for the second harvest at both soil fertility levels from the general competitive abilities of the species. Observed values confirm a high degree of over-complementation in almost all mixtures at the low fertility level, but very little at the high fertility level. Evidently the regressions are not sufficient to specify the exact relationships of all mixtures at these levels. That such inadequacies are not merely random effects of error but represent real deviations from the linear regression lines is of course indicated by the significant residual item in the analysis of variance after fitting regressions (table 5). It is worthwhile noting here that the major discrepancies between observed and expected at the higher fertility level 
involve mixtures with S.22 and it can be seen from fig. 3 that this species at this level shows points with greatest deviation from the line. Here particularly, therefore, we expect a high degree of specific competitive effects to exist. Although we have to treat the regression lines with caution once residual effects are significant (see Freeman and Perkins, 1971, Hardwick and Wood, 1972), it is probably fair to consider that over-complementation at the lower fertility levels may be more a question of balanced general (and hence predictable) competitive abilities, whereas the reactions at the higher fertility level are mixture- or monoculture-specific.

The ecological situations created by the two nutrient treatments at the second harvest are quite distinct and the differential reactions have ecological significance. Under the low fertility régime, competition will be for soil nutrients, while under the high fertility régime competition will be, presumably, for light. In the first situation the competitive advantages of constituent species in the different mixtures are relatively low, while overcomplementation is common (as in table 7). Thus mixture advantage will outweigh selective elimination of the weaker component and diversity of species will be maintained in the same way that heterozygote advantage secures maintenance of alleles in a gene pool. Conversely, in the high fertility situation, competitive advantage is increased and over-complementation is rare so that there would be selective elimination of species as equilibrium is approached. This entirely conforms with general agronomic experience and observation; several authors have noted that poor grasslands carry a greater diversity of plant species than rich ones, provided that the environment is not so unfavourable as to require specialised types of vegetation (e.g. Stapledon, 1913; Heddle, 1967).

\section{(c) Comparison of analytic methods}

At this stage we can consider the conclusions which can be drawn from these analyses and compare them with those inferred by Norrington-Davies.

Norrington-Davies seeks chiefly to separate competitive effects into three components. These are alpha $(\alpha)$ competition measuring a constant increase or decrease in one or more species when grown with others; beta $(\beta)$ competition measuring the extent to which the effect of one species upon another is a function of the species grown by themselves (as pure cultures) and $\bar{\beta}$ competition which gives the average beta over all species and is a measure of the extent to which large species suppress small species and/or are themselves increased in size when grown with small species. It is pointed out that alpha and $\bar{\beta}$ are to some extent confounded. The present analysis cannot be directly compared with that carried out by Norrington-Davies since effects are measured about the mean of the species so that the pure culture is no longer the main point of reference. Within the framework of the definitions, alpha competition would refer to the additive effects of species and associates. Correlated alpha, $\beta$ and $\hat{\beta}$ effects are included at least in part by the regression measurements and refer more specifically to our complementation estimates (formula 4) which compares mixture and monoculture yields as a special case.

Norrington-Davies' main conclusion was that the species with higher yields in pure stands are the strongest competitors and that these increase their yield in mixtures more than the associates are depressed, a situation 
represented in his analysis by either large alpha effects which are correlated with the species values or $\beta$ effects. Thus there was a tendency for mixture means to exceed the mid-constituent value: an effect which we have termed complementation.

In the present analysis we have shown that the relative performance of species in mixtures or monoculture is a function of the combined effect of associates and treatments which can to a large extent be measured by linear regression. In doing this we emphasise the essential relationship between environmental stress imposed by competitors (associates) and that imposed by other agencies (treatments). This aspect of competitional response we have termed general competitive ability and it presupposes that the response has a high degree of predictability over a number of competitive situations, and may equate to environmentally induced response under non-competitive conditions as discussed later.

Comparison of mixtures with constituent monocultures is considered as a special case in the general reaction of the varieties. Here the regression coefficients together with the mean species and associates effects provide parameters which measure mixture yields as well as the competitive advantage of the constituents. They afford measures of complementation, the level of this in relation to the monoculture values (defined as partial, full or over-complementation), and show how these change with treatments. Change in the order among the competing species as well as change in the magnitude of competition is specified by the parameters.

Where a significant proportion of the interaction between species and associates is not explained by linear regression, deviations from the regression lines help to distinguish mixtures with a specific competitive ability. In this way the analysis leads to a better understanding of the types of competitive interactions and focuses more closely on underlying causes.

\section{General discussion}

It must be stressed that the use of the regression technique in the present context is purely empirical. Our aim has been to discover to what extent data from competition experiments can be simply parameterised in this way so as to provide meaningful descriptions and predictions of competition effects. Regression on environmental means (= associate means here) has been criticised by Freeman and Perkins (1971) and Hardwick and Wood (1972) as introducing bias to the estimates of the coefficients and invalidating tests of significance in the analysis of variance. However, since the ratio of the between-associates variation and the error mean square is large for the experiments considered, the bias should not be great, and since we basically consider a diallel arrangement of a fixed number of lines (and hence associates), the interpretation of the analysis of variance table should not be seriously misleading (see Fripp and Caten, 1971). Clearly, substantial deviations from the regression lines will limit their use as predictive parameters. Hardwick and Wood (1972) point out that such deviations are not independent of the slopes, and that this arises inescapably from fitting lines to data which can only be properly represented in several dimensions. It follows that the presence of such deviations is a means of detecting differential responses by the genotypes to different sets of environmental variables, or differential responses by subsets of genotypes to the same set of environmental 
variables (Perkins and Jinks, 1968). A full parameterisation of the data would then require more elaborate models (e.g. multiple regression or principle component analysis, Perkins, 1972). Here the presence or absence of deviations from the regression lines has been used as a means of recognising specific, competitive properties of individual mixtures and hence as a basis for classifying general competitive abilities and specific competitive abilities.

In both experiments a high proportion of the interaction of species with associates could be explained on the basis of general competitive abilities. Indeed for six of the seven species in the first experiment (species 2 excluded) no specific competitive abilities could be detected. Consequently the effects could be largely specified by three parameters which could be estimated from the data. These are the species mean (v), the regression coefficient $(b)$ and the mean effect of associates $(a)$, which respectively measure the general vigour of the species, its sensitivity to competition and its aggressiveness. Using these parameters, formulae can be derived which provide descriptive and predictive measurements of the competitive advantage of species in particular combinations, and of the mixture yields relative to the yields of other mixtures and monocultures. In obtaining expected values and comparing these with observed, no standard errors have been calculated since at this stage we were more concerned with the applicability of the technique rather than with the accuracy of the experiment.

The results illustrate that the types of competitive phenomena which can derive from a situation involving only general competitive abilities vary greatly and depend on the correlations between the parameters $v, b$ and $a$ in the species under test. Of particular interest is the performance of mixtures relative to the components grown as monocultures. The sign of the complementation, defined as the increase or decrease in yield of the mixture over the mean yield of the component monocultures, depends on the cross relationships between $b$ and $a$ in the competing species (see formula 4 ). When the association is negative, which indicates a mixture between a species with high sensitivity to competitive stress and high aggressiveness and a species having a relatively low sensitivity coupled with low aggressiveness, positive complementation results. Negative complementation occurs when $b$ and $a$ are positively associated. In both experiments $b$ and $a$ were highly negatively correlated, so that positive complementation of the mixture yields was the rule. The magnitude of the complementation in mixtures relative to the yields of the monocultures depends on the way $v$ is associated with $a$ and hence also with $b$. Where $v$ and $a$ are positively associated, over-complementation may result. This may be positive, with mixtures outyielding the best monoculture, or negative, with mixtures yielding less than either monoculture, depending on the relationship between $b$ and $a$.

Wright (1971) recognises the interdependencies of the three parameters and has derived a single parameter $k$ which is a joint property of all competing populations. This parameter $k$ stems from the joint regression of the interaction components on associate and genotype means, and is effectively the correlation coefficient between $b$ and $v$. Its sign and magnitude, therefore, gives an indication of the general pattern of competition effects throughout all mixtures and monocultures. For instance, it can be used to estimate the mean complementation in mixtures relative to the mean of the monocultures. We have rather kept to the one-way regression on associate means in an attempt to characterise individual species, thus to describe and predict their 
performance in mixtures and monocultures and also in the second experiment to discover how these performances are affected by different treatments.

Developed in this way, the regression technique can be made the basis of a heuristic approach to the recognition of different competition situations through their consequences on the parameters. Thus where competition is entirely a matter of competing genotypes securing unequal shares of limited environmental resources (Clements et al., 1929; Donald, 1963) or of space generally (de Wit, 1960; Sandfaer, 1970), $v$ will be highly negatively correlated with $a$. On the other hand, this correlation will be weakened where one or more species show a general tolerance of crowding effects such as shade or plant chemical exudates, etc., or if one or more species have a general antagonistic effect on neighbours. These phenomena will have their own particular effects on the $b$ values which measure sensitivity to competition, and which will in turn determine the relative competitive abilities and the degree and direction of complementation in the mixtures. All these effects will be measured as general competitive abilities. Co-adaptational, including co-operational, effects and mutual antagonism will be represented by deviations from the regression line and classified as specific competitive abilities. Before the usefulness of this approach can be fully gauged, however, more information is required on the limits set by the interrelationships of the three parameters specifying general combining abilities.

A particular strength of the regression technique is in the combined analysis of data from a number of different treatments. In the second experiment, competing grass species were subject to treatment differences in soilfertility and time. A regression analysis of the combined data showed that a significant portion of the interaction of species with associates was explained as differences between the linear regressions of individual performance on the combined species and treatment effect. The overlapping effect of different associates (competition) and of treatments (general environment) were thus accommodated largely by the same set of regression lines within the limits of experimental error. This clearly underlines that genotypic response to environmental stress is largely the same whether the stress is obtained through competition or by other environmental agencies. As a consequence, the very different competitive relationships which existed between the species under the different treatments could be predicted, at least in part, in terms of general competitive abilities. These predictions were, however, complicated by the presence of specific competitive abilities for particular mixtures under particular treatments. It was also very clear that competition for light and competition for soil nutrients had quite different consequences.

Apart from their ecological significances, the results show that the regression technique may have direct application in plant breeding methodology. In herbage plants one of the more difficult problems is to relate observations on individual spaced clones to performance under competition in swards. The findings from the analysis of competition among grass species are important in this respect, particularly that competitive stress and other environmental stresses induce similar genotypic responses when measured by the regression technique. This argues that regression coefficients measuring the relative responses of spaced plants to varying treatments may be used to predict general competitive abilities in the sward. Some support for this argument is provided by the work of Samuel et al. (1970). At the same time 
it is important to consider the physiological basis of specific combining abilities (see Rhodes, 1969) so that the potentiality for breeding co-adapted forms may be properly assessed.

\section{REFERENCES}

BREESE, E. L. 1969. The measurement and significance of genotype-environment interactions in grasses. Heredity, 24, 27-44.

CLEMENTS, F. E., WEAVER, J. E., AND HANSON, H. C. 1929. Plant competition. An analysis of community functions. Carnegie Inst. Wash., Pub. No. 398.

DE wIT, C. T. 1960. On competition. Versl. landbouww, Onderz. Ned., 66, 1-82.

DonAld, c. M. 1963. Competition among crop and pasture plants. Adv. Agron., 15, 1-118.

DURRANT, A. 1965. Analysis of reciprocal differences in diallel crosses. Heredity, 20, 573607.

EVENARI, M. 1961. Chemical influences of other plants (Allelopathy). Handb. Pfanzenphys., 16, $691-709$.

FINLAY, K. W., AND WILKINson, G. N. 1963. The analysis of adaptation in a plant breeding programme. Aust. F. agric. Res., 14, 742-754.

FREEMAN, G. H., AND PERKINs, JEAN M. 1971. Environmental and genotype-environmental components of variability. VIII. Relations between genotypes grown in different environments and measures of these environments. Heredity, 27, 15-23.

FRIPP, YVONNE, J., AND GATEN, C. E. 1971. Genotype-environmental interactions in Schizophyllum commune. I. Analysis and character. Heredity, 27, 393-407.

HARDWICK, R. C., AND WOOD, J. T. 1972. Regression methods for studying genotypeenvironment interactions. Heredity, 28, 209-222.

HEDDLE, R. G. 1967. Long-term effects of fertilizers on herbage production. I. Yields and botanical composition. F. agric. Sci, Camb., 69, 425-431.

JACQUARD, P., AND GAPUTA, J. 1970. Comparaison de trois modelles d'analyse des relations sociales entre espèces végétales. Ann. Amelior. Plantes, 20, 115-158.

MATHER, K. 1961. Competition and co-operation. Symp. Soc. Exptl. Biol., 15, 264-282.

MCGILCHRIsT, C. A. 1965. Analysis of competition experiments. Biometrics, 21, 975-985.

MCGILCHRIST, C. A., AND TRENBATH, B. R. 1971. A revised analysis of plant competition experiments. Biometrics, 27, 659-671.

NORRINGTON-DAVIES, J. 1967. Application of diallel analysis to experiments in plant competition. Euphytica, 16, 391-406.

NORRINGTON-DAvIEs, J. 1968. Diallel analysis of competition between grass species. $\mathcal{F}$. agric. Sci., Camb., 71, 223-231.

PERKINS, JEAN M. 1972. The principle component analysis of genotype-environmental interactions and physical measures of the environment. Heredity, 29, 51-70.

PERKINS, JEAN M., AND JINKs, J. L. 1968. Environmental and genotype-environmental components of variability. III. Multiple lines and crosses. Heredity, 23, 339-356.

RHODEs, I. 1969. The yield, canopy structure and light interception of two ryegrass varieties in mixed culture and monoculture. F. Brit. Grassl. Soc., 24, 123-127.

SAMUEL, C. J. A., HILL, J., BREESE, E. L., AND DAVIEs, ALISON. 1970. Assessing and predicting environmental response in Lolium perenne. F. agric. Sci., Camb., 75, 1-9.

SANDFAER, JENS. 1970. An analysis of the competition between some barley varieties. Danish Atomic Energy Commission, Risö report no. 230, 1-114.

STAPLEDON, R. G. 1913. Botanical considerations affecting the care of grassland. Fournal of the board of Agriculture, 20, 393-399, 488-499.

WILliams, E. J. 1962. The analysis of competition experiments. Aust. F. Biol. Sci., 15, 509-525.

WRIGHT, A. J. 1971. The analysis and prediction of some two factor interactions in grass breeding. F. agric. Sci., Camb., 76, 301-306.

YATES, F., AND COCHRAN, w. G. 1938. The analysis of groups of experiments. F. agric. Sci., Camb., 28, 556-580. 